\title{
Vasoproliferative tumor of the retina
}

INSERM

\section{Source}

INSERM. (1999). Orphanet: an online rare disease and orphan drug data base.

Vasoproliferative tumor of the retina. ORPHA:353356

Vasoproliferative tumor of the retina is a rare, benign, retinal vascular disease characterized by solitary or multiple, unilateral or bilateral, intra-retinal tumor(s), usually located in the peripheral infero-temporal quadrant, and often associated with sub- and intraretinal exudates, epiretinal membranes, exudative retinal detachment and cystoid macular edema, as well as, occasionally, retinal and vitreous hemorrhage. Patients may present with visual loss, floaters, and/or photopsia. Association with various conditions, such as retinitis pigmentosa, congenital retinal toxoplasmosis, retinopathy of prematurity, or coloboma, has been reported. 